Research Article

\title{
Innovative first order elimination kinetics working model for easy learning
}

\author{
Navin Budania ${ }^{1}$, Arka Mondal ${ }^{1}$, Vinod Bharadwaj ${ }^{1}$, \\ Vijay Yadav $^{2}$, Priyamvada Sharma ${ }^{1}$
}

\begin{abstract}
${ }^{1}$ Department of Pharmacology, SHKM-GMC, Nalhar, Mewat, Haryana, India

${ }^{2}$ Department of Pharmacology, MIMS, Barabanki, Uttar

Pradesh -East, India
\end{abstract}

Received: 08 March 2016

Revised: 21 April 2016

Accepted: 10 May 2016

\section{*Correspondence to:}

Dr. Navin Budania,

Email: abhishekparleg

@gmail.com)

Copyright: (C) the author(s), publisher and licensee Medip Academy. This is an openaccess article distributed under the terms of the Creative Commons Attribution NonCommercial License, which permits unrestricted noncommercial use, distribution, and reproduction in any medium, provided the original work is properly cited.

\begin{abstract}
Background: General pharmacology is the backbone of therapeutic pharmacology. In general pharmacology, pharmacokinetics is a very difficult topic for undergraduate medical students. Knowledge of the kinetics and of the effects of drugs is necessary for the correct use of drugs in therapy. As in the body most of the drugs follow first order elimination kinetics, so it is necessary for all students to know about basic concept of first order kinetics. This can be easily understood by using working models. Our present study is a step in that direction. The objective of this study was planned to develop first order elimination kinetics working models to teach pharmacokinetics principle to the under graduate medical students.

Methods: The current study was planned and executed by the department of pharmacology in SHKM government medical college, Mewat, Haryana, India in the first quarter of 2016. This model was developed from household waste materials like thermocol sheets, coke bottles, waste water pipe, colour etc.

Results: As we know learning is better with live experimentation as compare to theoretical learning, so difficult topics such as elimination kinetics will be taught by help of working models.

Conclusions: First order elimination kinetics is easily understood with the help of above working model. More and more working models could be developed for teaching difficult topics.
\end{abstract}

Keywords: Pharmacokinetics, Working models, First order elimination kinetics

\section{INTRODUCTION}

Pharmacokinetic models are used to describe the time dependent disposition and absorption of a substance in a living system. As we know pharmacokinetics is the part of general pharmacology which is the backbone of therapeutic pharmacology. ${ }^{1}$ Generally the undergraduate medical students face difficulty to clear the concept of elimination kinetics and also applying this concept to patient care. Elimination kinetics can be used to estimate optimal drug dosage regimens in different therapeutic situations. ${ }^{2}$ Knowledge of the kinetics and of the effects of drugs is necessary for the correct use of drugs in therapy. Drug elimination is a part of pharmacokinetics study. Drug elimination may occur through biotransformation and by the passage of molecules from the blood to the outside of the body through urine, bile or other routes. There is lots of confusion between zero order kinetics and first order kinetics for undergraduate medical students. Therefore, an important question is whether teaching students using an approach that deliberately and systematically integrates the activities of these disciplines will enhance our understanding of drugs, and the efficiency and effectiveness of drug discovery 
and development. ${ }^{1}$ Elimination kinetics can be first order or zero order. As in the body most of the drugs follow first order elimination kinetics, so it is necessary for all students to know about basic concept of first order kinetics. This can be easily gained by the help of working models.

\section{METHODS}

This model was developed from household waste materials like thermocol sheets, coke bottles, waste water pipe, colour, marker etc.

\section{Designing of model}

The model was prepared from two $500 \mathrm{ml}$ coke bottle. The upper bottle is cut from the bottom so, the fluid/drug was administrated from above. In lower part near the neck of the bottle vertical holes of equal size are made to maintain the clearance rate constant. The lower bottle was cut from above at midpoint of the bottle. It mainly acts as a reservoir which passed the fluid/drug through a pipe, which is inserted in the lower part of the bottle. The upper bottle is inserted upside-down in the lower bottle. The amount of fluid which is collected from above bottle is passed through this pipe, which helps in calculating the elimination rate of the fluid/drug. The model was fixed on a thermocol sheet.

\section{Procedure}

First we prepared colourful fluid by adding some milk in water which was substitute to drug. Then we filtered the solute particle of milk in order to make fluid clear so that it can easily pass through the pores of upper bottle. The fluid is added above the maximum marking in the upper bottle. At the same time video recording is started by help of mobile VLC media player, which show time in their recording.

The marking of upper bottle is made by help of filling calculated amount of fluid in the upper bottle after closing the lower pores by thumb and finger. Here the marking of the colour fluid in the upper bottle represent the drug concentration. In this experiment $100 \mathrm{ml}$ of fluid is equivalent to $1 \mathrm{C}$ (concentration) and $200 \mathrm{ml}$ is equivalent to $2 \mathrm{C}$ of the drug in the plasma. So, higher is the marking higher is the plasma concentration.

\section{RESULTS}

First filled the upper bottle above the maximum marking by the colourful fluid which represent drug.At the time video recording is started in VLC media player and the Screen snap-shot was taken from the video recording and further analysed

As we have seen in (Figure 1). The concentration of drug$\mathrm{X}$ (colourful white fluid) at 12 seconds was 4C (equivalent to $400 \mathrm{ml}$ ), at 47 seconds was 2C (Figure 2), at 1 minute 22 seconds the concentration become $1 \mathrm{C}$ (Figure 3), at 1 minute 57 seconds the concentration become $1 / 2 \mathrm{C}$ (Figure 4 ) and it 2 minute 32 seconds the concentration become $1 / 4 \mathrm{C}$ (Figure 5). Time taken from $4 \mathrm{C}$ to $2 \mathrm{C}, 2 \mathrm{C}$ to $1 \mathrm{C}, 1 \mathrm{C}$ to $1 / 2 \mathrm{C}$ and $1 / 2 \mathrm{C}$ to $1 / 4 \mathrm{C}$ is 35 sec.as we see in the above figures the rate of elimination of drugs through pipe was decreased with decrease in plasma concentration.

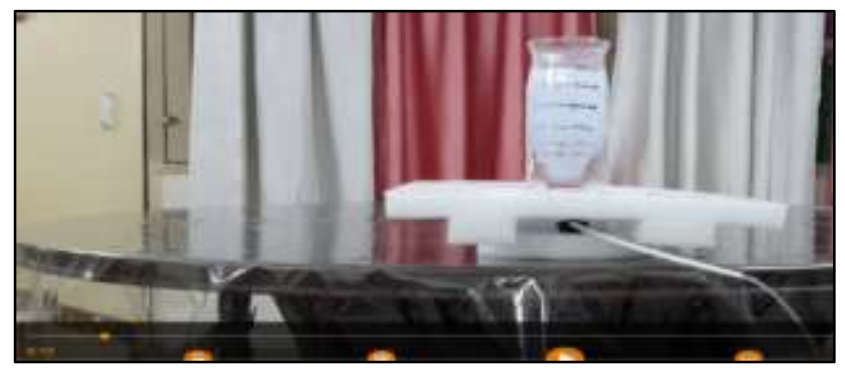

Figure 1: At 00:12 second the concentration of drug $X$ is $4 \mathrm{C}$.

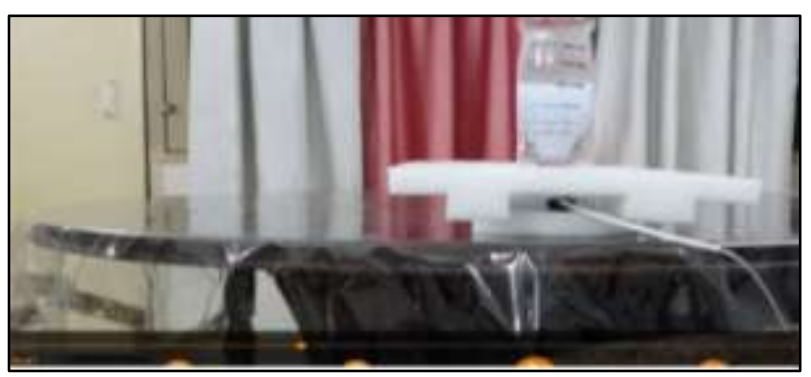

Figure 2: At 0:47 second the concentration of drug $\mathrm{X}$ is $2 \mathrm{C}$.

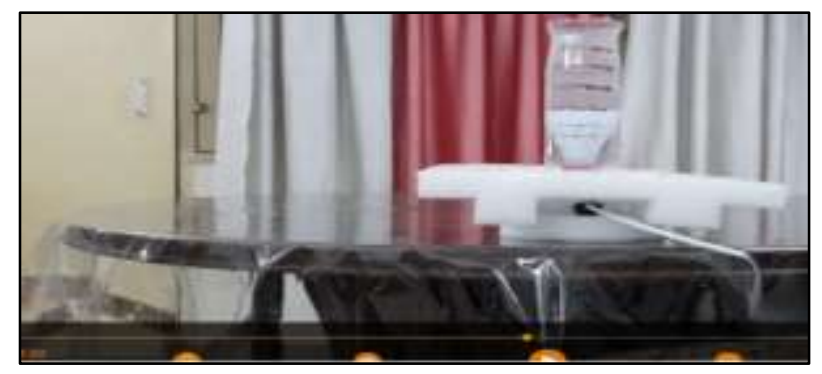

Figure 3: At 1:22 second the concentration of drug $X$ is $1 \mathrm{C}$.

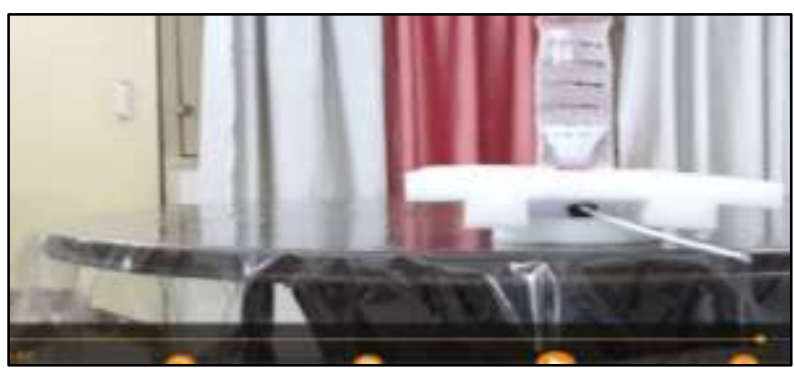

Figure 4: At 1:57 second the concentration of drug $X$ is $1 / 2 \mathrm{C}$. 


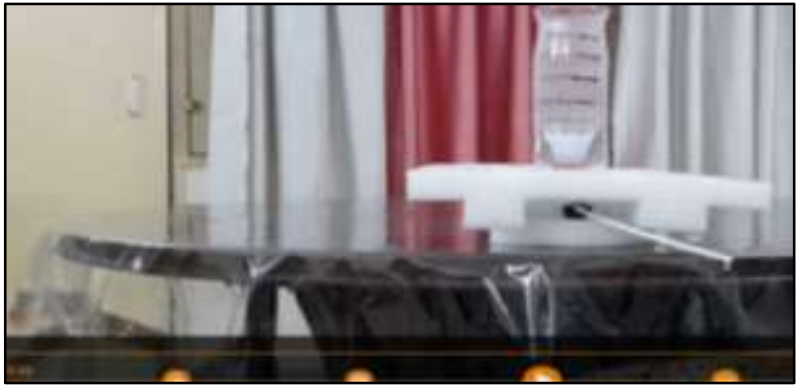

Figure 5: At 2:32 second the concentration of drug $X$ is $1 / 4 \mathrm{C}$.

\section{DISCUSSION}

In first order elimination kinetics the $t 1 / 2$ of the drug remains constant irrespective of the plasma concentration of the drug. ${ }^{4,7}$ In this study the concentration of the drug $\mathrm{X}$ is reduced by half of its previous value after every 35 sec. So, the drug-X follows first order kinetics. In first order kinetics the elimination rate varies with plasma concentration of drugs. ${ }^{5,7}$ The rate of elimination of drug which follows first order kinetics is higher at higher concentration and lower at lower plasma concentration i.e. the rate is directly proportional to the plasma concentration. ${ }^{6,8}$ In (Figure 1-5) there is decrease in rate of elimination of drugs through excretion pipe with decrease in the plasma concentration of the drug. The rate of elimination of drug- $\mathrm{X}$ is highest at $4 \mathrm{C}$ and lowest at $1 / 4 \mathrm{C}$. So, here the drug- $\mathrm{x}$ follows first order elimination kinetics which can be taught easily to the UG students. Therefore the students learn first order elimination kinetic principle easily with the help of this model. Learning by working model is better as compared to theoretical. Bonwell and Eison conclude that active learning leads to better student's attitudes and improvements in student's thinking. ${ }^{9}$ In addition to this Felder et al. also recommended active learning, among various teaching methods that work. ${ }^{10}$ Recently in a meta-analysis of 225 studies that compare STEM classes taught using various active learning approaches with classes taught via lecture. "The results indicate that average examination scores improved by about $6 \%$ in active learning sessions, and that student in classes with traditional lecturing were 1.5 times more likely to fail than were students in classes with active learning.". 3 So difficult topics such as elimination kinetics could be taught by using working models.

\section{CONCLUSION}

First order elimination kinetics is easily understood with the help of above working model. More and more working models could be developed for teaching difficult topics.

Funding: No funding sources Conflict of interest: None declared Ethical approval: Not required

\section{REFERENCES}

1. Gabrielsson J, Weiner D. Pharmacokineticpharmacodynamic data analysis: concepts and applications, swedish pharmaceutical press. Stockholm; 2010.

2. Rescigno A, Segre G. Drug and tracer kinetics. Blaisdell, Waltham (Mass); 1966.

3. Freeman S, Eddy SL, McDonough M, Smith MK, Okorafor N, Jordt H, et al. Active learning increases student performance in science, engineering, and mathematics. Proceedings of the National Academy of Sciences (PNAS).2014;111(23):8410-5.

4. Narsimhan B, Mallapragada SK, Peppas NA. Release kinetics, data interpretation. Encyclopedia of Controlled Drug Delivery. E Mathiowitz ed., John Wiley and Sons. 1999;921-35.

5. Ito S, Lee A. Drug excretion into breast milk: Overview. Adv Drug Deliv Rev. 2003;55:617-27.

6. Stern P, Radovic N, Buljubasic S. Urinary excretion of methylamphetamine in man. Nature. 1965;206:1260-1.

7. Sharma KK, Sharma HL, Eds., Principles of Pharmacology, $2^{\text {nd }}$ ed. India; 2011.

8. Levine RR, Walsh CT, Rochelle D. Pharmacology: drug actions and reactions, $7^{\text {th }}$ ed. Florida; 2004.

9. Bonwell CC, Eison JA. Active learning: creating excitement in the classroom. ASHEERIC higher education report no.1, George Washington University, Washington, DC; 1991.

10. Felder RD, Stice WJ, Rugarcia A. The future of engineering education: II. Teaching methods that work, chemical engineering education. 2000;34(1):26-39.

Cite this article as: Budania N, Mondal A, Bharadwaj V, Yadav V, Sharma P. Innovative first order elimination kinetics working model for easy learning. Int J Basic Clin Pharmacol 2016;5:862-4. 